\title{
Empreendedorismo e segmento Premium: um estudo em três empresas de Uberlândia-MG
}

Michelle Castro Carrijo ${ }^{1}$

Marcia Mitie Durante Maemura ${ }^{1}$

Beatriz Chuffi Rodrigues ${ }^{1}$

${ }^{1}$ Universidade Federal de Uberlândia 


\section{Empreendedorismo e segmento Premium: um estudo em três empresas de Uberlândia-MG}

Resumo: O segmento Premium tem recebido grande atenção devido ao avanço progressivo que tem apresentado, em especial, no Brasil. O estudo tem como objetivos compreender como empreendedores desse segmento o definem, identificar qual o perfil desses empreendedores e, por fim, como compreendem o desempenho do segmento empreendimento no mercado, particularmente, em um momento de instabilidade econômica. Para tanto, foi realizada uma pesquisa qualitativa, com base em técnicas de pesquisa bibliográfica, documental e a realização de entrevistas com três empreendedores do segmento Premium da cidade de Uberlândia-MG. Como resultado, pôde-se identificar a tendência na busca por diferenciação, em especial, devido a uma mudança percebida no comportamento do consumidor e também na postura do empreendedor ao conceber seu negócio, atento à geração de valor na oferta de produtos e serviços mais elaborados que são reconhecidos pelos seus consumidores e, por fim, que esse segmento parece ser relativamente menos afetado por crises econômicas.

Palavras-chave: Segmento Premium. Empreendedor. Consumidor. Diferenciação.

\section{Introdução}

O interesse dos meios acadêmico, empresarial e governamental brasileiros acerca do empreendedorismo relaciona-se com a identificação do tema com fatores como a criatividade, inovação e oportunidades de negócios, sobretudo em momentos de instabilidade econômica e aumento do desemprego. Neste sentido, o investimento em um negócio próprio revela-se um meio de contornar as dificuldades econômicas, tendo em vista a possibilidade de se explorar novas oportunidades e nichos de mercado.

Desde 2015, o Brasil apresenta cenário econômico instável e com elevadas taxas de desemprego. A despeito destes indicadores, cresce o consumo de bens e serviços de elevada qualidade e valor agregado: o segmento Premium (como sinalizam Valim (2017) e Dias (2016), dentre outros). O que impulsionou a criação de novos empreendimentos com este enfoque. De acordo com Galhanone e Toledo (2009), este segmento é direcionado a consumidores exigentes quanto aos produtos e serviços que estão adquirindo. Segundo os autores, tais consumidores buscam algo além de suprir necessidades básicas, proporcionando experiências diferenciadas.

De um modo geral, o segmento Premium é caracterizado pelo alto nível de qualidade oferecida, cujos preços praticados são mais elevados, sendo mais exclusivo que um produto comum, porém inferior a um produto de luxo (DINIZ, 2012; PASSARELLI, 2010). Essa busca cada vez maior pelo consumidor por valor agregado alavancou de forma significativa o desenvolvimento do segmento Premium. Se considerando o destaque deste tipo de empreendimento, cabe investigar como os empreendedores definem este mercado, as motivações que os levaram a tal investimento, o que esperam e quais os resultados alcançados.
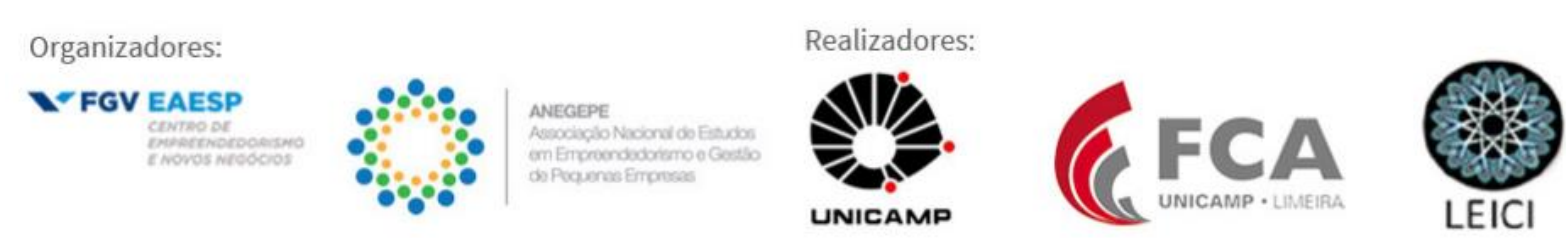
Portanto, a partir da recente ascensão do mercado Premium e devido ao interesse em aprofundar o conhecimento acerca deste mercado no âmbito do empreendedorismo, o presente estudo tem como objetivo caracterizar os empreendimentos voltados ao mercado Premium na cidade de Uberlândia/MG. Para atender ao objetivo, a pesquisa se propôs a elencar os aspectos gerais do mercado Premium, apontar as características dos empreendedores e empreendimentos em Uberlândia, além de descrever como tem sido a inserção deste segmento no mercado local.

O artigo foi estruturado da seguinte forma: depois da introdução; na primeira seção é abordado o Referencial Teórico; a segunda seção trata dos procedimentos metodológicos adotados para a condução do estudo. Na terceira seção se faz uma contextualização do crescimento da atividade empreendedora e do setor Premium no Brasil; a quarta seção, é realizada a análise dos resultados encontrados nas entrevistas realizadas com três empresários do segmento Premium de Uberlândia- MG. Por fim, tem-se as Considerações Finais.

\section{Referencial Teórico}

Embora tenha assumido um papel de maior destaque nos últimos anos, o conceito de empreendedorismo é tão antigo quanto o intercâmbio e o comércio entre indivíduos. Ainda no início do século XX o economista Joseph Schumpeter (1883-1950) destaca o conceito de "Destruição Criativa", na qual destaca as relações entre o empreendedorismo e a inovação. Neste conceito, o empreendedor é o precursor da inovação no mercado. Esta (a inovação) gerada impulsiona a mudança, estabelecendo uma relação direta entre empreendedorismo, inovação e desenvolvimento econômico.

Já o termo empreendedorismo passa a ser utilizado isoladamente a partir das mudanças ocorridas na base econômica mundial com o advento modelo fordista de produção (meados da década de 1920). O termo começou a ser associado à criatividade e à inovação, aliado também à identificação de oportunidades (LEITE, 2000; DORNELAS, 2008; MARIANO e MAYER, 2011; HISRICH; PETERS, 2009; LANDSTRÖM, HARIRCHI, ASTRÖM, 2012; VERGA e SILVA, 2014; MACHADO, et al, 2015).

Cabe ressaltar a distinção entre empreendedorismo e o papel do empresário. $\mathrm{O}$ empreendedorismo compreende a implantação de inovações no mercado e difusão de novas ideias. O empresário, por sua vez, tem como função garantir a execução da inovação (SCHUMPETER, 1961).

Drucker (1986), porém, defende que não se pode considerar todos os novos negócios como "empreendimentos". Segundo o autor, para que sejam organizações empreendedoras, elas devem criar algo novo e diferente, mudando ou transformando valores. Caberia ao empresário assumir o papel de renovar conceitos pré-determinados na sociedade, criar novas perspectivas de produtos e serviços, gerar empregos e reduzir a pobreza de forma criativa.

Bessant e Tidd (2009; p. 288) ponderam que "[...] empreendedorismo é muito mais que a criação de um novo negócio.". Os autores mostram que abrir um negócio não torna necessariamente uma pessoa empreendedora, e assim retomam a perspectiva de inovação e criatividade envolvidas no conceito schumpeteriano (no qual o empreendedorismo deve promover transformação e agregar valor).

O Global Entrepreneurship Monitor (GEM) define o empreendedorismo como “[...] qualquer tentativa de criação e desenvolvimento de novos negócios ou criação de novas

Organizadores:
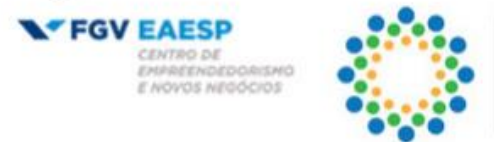

AEEGPE

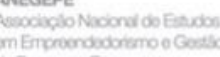

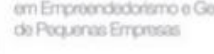
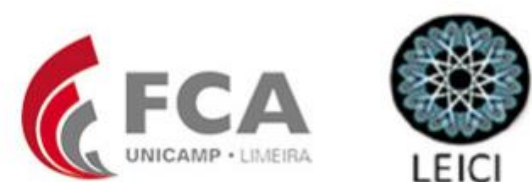
empresas, como o trabalho por conta própria, uma nova organização empresarial, ou a expansão de uma empresa já existente, por um indivíduo, uma equipe de pessoas, ou um negócio estabelecido" (GEM 2016, p. 21). Esta concepção destaca o potencial risco assumido pelo empreendedor ao iniciar um novo empreendimento.

Percebe-se desde a visão de Schumpeter (1961) até as atuais concepções sobre o empreendedorismo que o empreendedor é o precursor da transformação necessária para o desenvolvimento da sociedade, por meio da destruição criativa. Neste sentido, Drucker (1986) reforça que o empreendedor se destaca pela busca por mudança e visão de oportunidade, que é entendida como a identificação de necessidades do mercado que ainda não foram atendidas de maneira satisfatória. Caberia ao empreendedor encontrar oportunidades para criar algo novo, com o intuito de preencher estas lacunas.

Mariano e Mayer (2011) apontam que é possível identificar características semelhantes (como a criatividade e a inovação) entre os grandes nomes do empreendedorismo. Tais características poderiam ser traduzidas pelos envolvidos realizarem algo novo e diferente, agregando valor à sociedade, gerando desenvolvimento socioeconômico. Para Longenecker et al. (2007), o empreendedor é a pessoa que inicia e/ou opera um negócio para realizar uma ideia ou projeto pessoal assumindo riscos e responsabilidades, inovando continuamente. Rocha e Freitas (2014) observam, contudo, que o empreendedor não é caracterizado pela assunção de riscos incontroláveis. Segundo os autores, o empreendedor classifica e analisa os riscos envolvidos na abertura de um empreendimento - para a partir daí, averiguar qual a sua real capacidade de assumi-los.

Sánchez (2013) observa, também, que com o aumento da experiência empreendedora, maiores são também os riscos assumidos pelo empreendedor. $\mathrm{O}$ autor destaca a experiência em "primeira pessoa", na qual o empreendedor, já ciente do métier de suas atividades, busca minimizar pendências cotidianas, buscando reforçar aspectos positivos e arriscar soluções para problemas potencialmente graves, que possam vir a futuramente arriscar a continuidade do empreendimento.

Dornelas (2008) descreve a existência de fatores pessoais e externos que auxiliam o indivíduo a desenvolver atividade empreendedora. Para o autor, os fatores pessoais, em geral, estão relacionados com as habilidades do indivíduo (se a pessoa é criativa, gosta de trabalhar em equipe, é persistente). Para o autor, essa pessoa possui aspectos que lhe favorecem quanto ao empreendedorismo. Já os fatores externos (como progresso tecnológico, presença de incubadoras, legislação favorável, fatores econômicos, bem como a tendência de terceirização das empresas, precarização das relações de trabalho, aumento da presença das mulheres no mercado) são alguns dos aspectos ambientais que podem levar ao aumento do processo empreendedor (DORNELAS, 2008).

Além da influência do contexto, existe uma série de motivos que fazem com que a pessoa tenha a iniciativa de criar o próprio negócio. Segundo levantamento realizado por Degen (2009), os motivos mais comuns são a vontade de ganhar mais dinheiro, sair da rotina do emprego, ser o responsável pelo próprio futuro, necessidade de provar a própria capacidade e desejo de criar algo que gere reconhecimento e benefícios para si e para a sociedade. Além destes fatores, o autor observa a existência de dificuldades, especialmente no início da atividade empreendedora (exigência de uma grande dedicação, muitas horas de trabalho, investimento e sacrifícios em geral) são alguns exemplos das dificuldades de empreender.
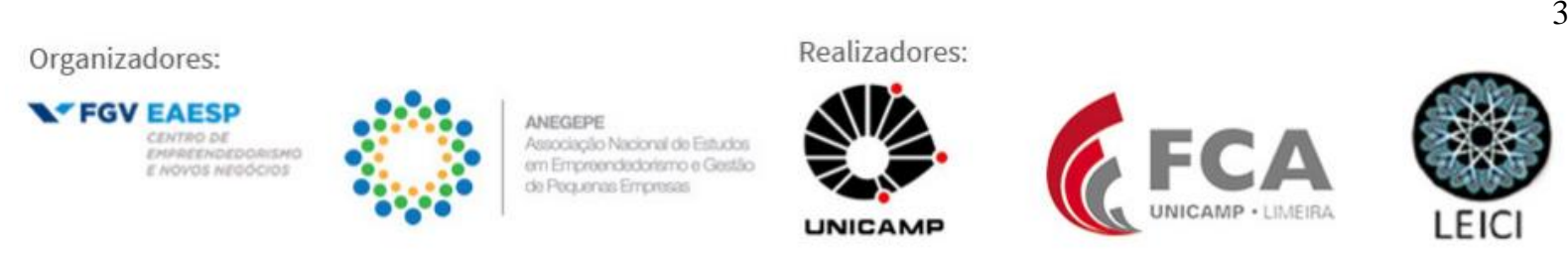
Outros motivos considerados "antecedentes" da ação empreendedora igualmente relevantes são destacados por Nyock, Ilouga e Hikkerova (2013). Para os autores, a socialização prévia com empreendedores (como, por exemplo, com a família) podem estimular o indivíduo a buscar outras possibilidades de abertura de negócios.

Leite (2000) menciona a necessidade de sobrevivência e o desejo de realização como motivos para geração de um novo negócio. Completando este fato, Mariano e Mayer (2011) mencionam que em países desenvolvidos a maioria dos empreendimentos é por oportunidade (ou seja, empreendedores não foram forçados por necessidades, como o desemprego, a abrirem um negócio) e a taxa de juros para captação de recursos para a abertura do empreendimento é menor.

Aos poucos, o relato observado por Mariano e Mayer (2011) em outros países passa a vigorar também no Brasil. Segundo dados do GEM (2016), até 2002 no Brasil era predominante o empreendedorismo por necessidade, porém, em meados de 2003 houve uma mudança e as taxas de empreendedorismo por oportunidade superaram o empreendedorismo por necessidade. Ainda segundo o estudo, em 2014 as taxas de desemprego passaram a aumentar e, consequentemente, a taxa de empreendedorismo por oportunidade reduziu, se aproximando do empreendedorismo por necessidade.

\section{Metodologia}

O artigo apresenta características qualitativas, caracterizado por não apresentar métodos estatísticos de medição para análise de dados e, portanto, envolve a coleta de dados descritivos (GODOY, 1995). Além disso, ainda segundo o autor, este tipo de investigação é adequado em casos em que a pesquisa é exploratória e o problema em questão é pouco conhecido.

O procedimento metodológico definido do ponto de vista dos objetivos do artigo foi a pesquisa exploratória que "[...] tem como objetivo proporcionar maior familiaridade com o problema, com vistas a torná-lo mais explícito ou a construir hipóteses. " (GIL, 2002, p. 41; PRODANOV; FREITAS, 2013, p. 127).

Dada a natureza desta pesquisa a mesma envolve os seguintes aspectos: (a) levantamento bibliográfico; (b) entrevistas com pessoas que tiveram experiências práticas com o problema pesquisado; e (c) análise de exemplos que estimulam a compreensão.

Quanto à coleta dos dados, foram realizadas entrevistas semiestruturadas se utilizando um roteiro com uma série de perguntas para guiar a entrevista. Este roteiro foi estruturado de forma a existir flexibilidade caso o entrevistado decidisse explanar aspectos de suas respostas. Foram realizadas entrevistas com três empresários da cidade de Uberlândia/MG, sendo um deles do ramo imobiliário e, outros dois, do ramo alimentício. Este público-alvo foi selecionado de maneira intencional e não amostral (COOPER; SCHINDLER, 2016) se considerando a proximidade dos pesquisadores com os proprietários dessas empresas. Os dados foram registrados de forma escrita, registrados pelos pesquisadores e posteriormente analisados.

Como anteriormente relatado, para a realização das entrevistas, foi elaborado um roteiro de entrevista. Previsivelmente, por se tratarem de temas correlatos, as respostas dadas pelos entrevistados não necessariamente seguiram a ordem proposta pelo roteiro, muito embora todas as suas temáticas tenham sido contempladas. As entrevistas tiveram duração média de 45 minutos e, apesar das diferentes características de cada empresário e empreendimento, algumas
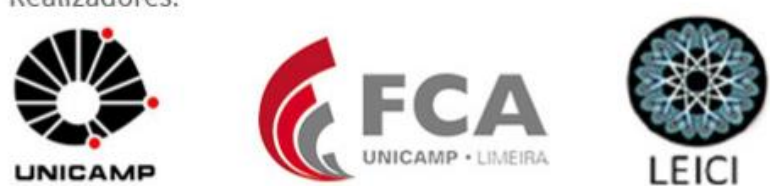
respostas eram coincidentes. O roteiro de entrevista foi estruturado em seis partes, descritas no Quadro1.

Quadro 1 - Estruturação do roteiro de entrevista

\begin{tabular}{|l|l|}
\hline Parte 1 & Identificação do perfil do entrevistado \\
\hline Parte 2 & Identificação do empreendimento \\
\hline Parte 3 & Motivação e influências para abertura do empreendimento \\
\hline Parte 4 & Compreensão do conceito de "segmento Premium" \\
\hline Parte 5 & Empreendendo no "segmento Premium" \\
\hline
\end{tabular}

Fonte: Elaborado pelos autores.

Obedecendo a critérios de sigilo e confidencialidade anteriormente acordados junto ao público entrevistado, optou-se por denominá-los por Entrevistado A (empreendimento de espetinhos Gourmet); Entrevistado B (hamburgueria) e Entrevistado C (o negócio do ramo imobiliário).

\section{$4 O$ crescimento da atividade empreendedora e o segmento premium no Brasil}

Segundo o GEM (2016), o Brasil foi considerado o país mais empreendedor do mundo. Trata-se do maior estudo sobre empreendedorismo no mundo, sendo realizado desde 1999. Realizada anualmente desde 2007, a pesquisa abrange quase 100 países, cobrindo $75 \%$ da população global.

O estudo afirma que a taxa total de empreendedorismo, em 2015, foi de $36 \%$ - algo menor do que a taxa observada em 2015 (39,3\%). Além disso, o estudo aponta que todas as faixas etárias apresentam índices significativos de empreendedorismo, porém com menores taxas entre os indivíduos com maior faixa etária (em 2015, indivíduos empreendedores entre 55 e 64 anos totalizavam $15 \%$ dos indivíduos pesquisados na amostra). É válido se mencionar que o Brasil continua sendo o país mais empreendedor dos BRICs desde 2014.

O tema "empreendedorismo" ocupa cada vez mais espaço na mídia. De acordo com o estudo "Cultura Empreendedora no Brasil" (ENDEAVOR; GRUPO TROIANO, 2014), 56\% dos entrevistados afirmam terem visto muitas matérias sobre o assunto na mídia. Ainda segundo a pesquisa (2014), mais da metade dos entrevistados (61\%) afirmaram que pretendem abrir um negócio próprio nos próximos cinco anos. Além disso, $82 \%$ dos entrevistados responderam que o desenvolvimento do Brasil depende ou depende muito da iniciativa empreendedora (ENDEAVOR; GRUPO TROIANO, 2014).

Apesar do momento econômico desfavorável, o mercado brasileiro se mostra cada vez mais competitivo, beneficiando o consumidor com o aumento do leque de opções na hora da tomada de decisão de compra. Neste processo, deve-se considerar não apenas a operação da empresa, mas também seus fornecedores, distribuidor e clientes - e, sobretudo, dada a acirrada concorrência o objetivo da empresa também passa a ser criar e entregar valor aos consumidores (KOTLER; KELLER, 2014).

Nesta busca pela entrega de valor, as empresas desenvolvem estratégias para buscar aumentar a percepção de qualidade de produto/serviço do consumidor. Essa busca por maior
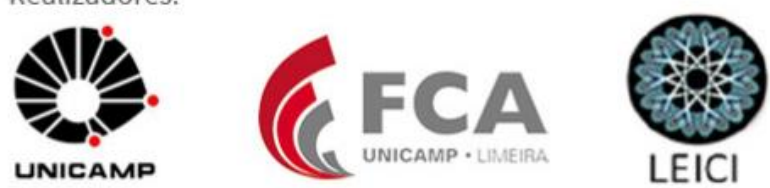
percepção de qualidade pode ser acompanhada, também, de preços e custos mais elevados. Como observam Churchill e Peter (2013), na procura pela oferta de valor superior, as empresas não podem tão-somente reagir ao mercado e sim ter iniciativa para mudar seu panorama e melhorar a própria posição competitiva.

Como é próprio da atividade empreendedora (e buscando conscientemente a continuidade das empresas), empreendedores buscam constantemente alternativas viáveis de desenvolvimento de novas ideias que venham a diferenciar seus produtos e serviços. Uma das diferentes formas pelas quais o empreendedor pode desenvolver novas alternativas é o design thinking - técnica caracterizada pela busca de inovações por parte da empresa a partir das perspectivas dos clientes (SEBRAE, 2016). O conceito do design thinking é focado na busca de se aprofundar na vida e hábitos dos consumidores, identificando comportamentos e necessidades futuras. Fazendo-se uso deste processo, espera-se descobrir o inexplorado e obter algo realmente funcional (SEBRAE, 2016).

Galhanone e Toledo (2009) destacam que a constante sofisticação da sociedade tem estimulado uma procura que vai além do atendimento das necessidades básicas, englobando também produtos e serviços simbólicos e emocionais. Os autores também mencionam que nas últimas décadas houve um aumento no mercado de luxo e Premium, por conta do crescimento do padrão de vida em países emergentes. Estes fatores ajudaram a popularizar produtos que hoje não são consumidos exclusivamente pela classe média e alta, podendo ser denominados "luxos acessíveis" ou Premium, para referenciar produtos que possuem valor mais alto e oferecem um diferencial (MADI; AMARAL, 2014).

Todavia, é preciso entender as demandas do consumidor Premium, que busca não apenas a alta qualidade ou um produto básico, mas também uma experiência de compra diferenciada, um produto que proporcione mais benefícios, além de atender à necessidade básica. Diniz (2012) menciona que os fatores que diferenciam os produtos Premium são: a apresentação do produto, sua qualidade intrínseca, preço elevado e exclusividade.

Produtos Premium podem também ser definidos como aqueles que estão "situados entre os produtos comuns e os de luxo" (STREHLAU, 2008, p.33). Um ponto interessante levantado por este autor se refere à questão do consumo de produtos Premium por parte de jovens de até 625 anos que, apesar de possuírem um menor poder aquisitivo, possuem maior propensão a seguir tendências.

Alguns segmentos têm se destacado no Brasil no quesito de consumo Premium. Dentre eles, pode-se destacar a área alimentícia (paleterias, hamburguerias, produtos orgânicos, entre outros) e de cerveja. Para a primeira, vem sendo utilizada também a nomenclatura Gourmet, que expressa a sofisticação e diferenciação do produto e na segunda, as cervejas Premium, em geral, são conhecidas como artesanais, sendo estas mais elaboradas, produzidas em baixa quantidade e que não são pasteurizadas (SILVA, 2014).

De acordo com Passarelli (2010), houve uma mudança do público consumidor de produtos Gourmet nos últimos anos. Se até meados da década de 1980, o mercado de luxo era dominado por fortunas e famílias tradicionais, a partir da década de 1990, com a queda das barreiras protecionistas e flexibilização de barreiras comerciais promovidas pelo então governo Collor, este perfil mudou sensivelmente. Com o advento do Plano real e controle da inflação, a economia nacional sofreu grandes alterações positivas, que vieram a estimular a criação de novas fortunas e novos players no mercado nacional. Segundo o autor, uma jovem e

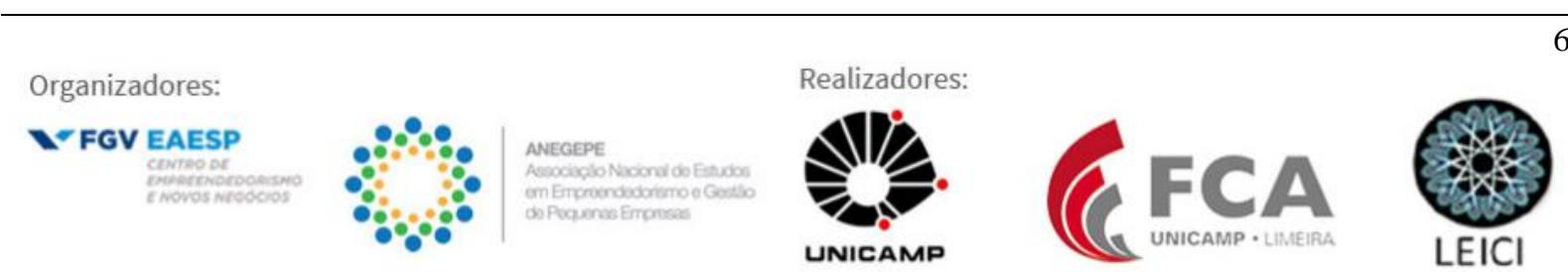


endinheirada elite ascendeu. Essa nova elite, composta por muitos herdeiros, mas também composta por empreendedores, alavancou o início de novas experiências de consumo, na busca da satisfação de desejos recém-descobertos por viagens e com poder aquisitivo 'para tanto. Para o autor, este público buscava, prioritariamente, confirmação de um estilo de vida, status, beleza, prazer e emoção ao consumirem produtos ditos "diferenciados".

Kotler e Keller (2014) relatam ser necessário compreender as necessidades do consumidor e o que impulsiona a sua compra. Para os autores, conforme o consumidor avalia o custo e o percebe como "baixo" em comparado à experiência agregada que receberá, maior a probabilidade de o cliente perceber maior valor quanto àquele produto/serviço. Outrossim, a satisfação das necessidades e dos desejos específicos do consumidor podem levar lealdade à marca, e esse vínculo entre marca e consumidor dificilmente é quebrado pela concorrência (REICHHELD, 2000).

Para Dubois, Czellar e Laurent (2005), não só no Brasil, mas no mundo todo, a partir da década de 1980, o consumidor tornou-se mais sofisticado e exigente, já que, graças às constantes inovações na área de tecnologia de informação, possui um alto grau de acesso à informação. Esta informação influencia fatores culturais, sociais, pessoais e psicológicos e, por estas razões, possui maior entendimento sobre produtos, serviços e estratégias de marketing, o que confere maior poder ao consumidor e demanda maior atenção por parte das empresas. Para Kotler e Keller (2014) as culturas são compostas por subculturas que determinam características específicas para seus membros e neste sentido, Catry (2003) relata que as pessoas muitas vezes são levadas a consumir determinados produtos para fazerem parte de um determinado grupo de referência. Mattoso e De Sá (2013) afirmam que a influência social no consumo nunca esteve tão forte - originando, inclusive, "tribos" de "incluídos" e "excluídos", especialmente dentre a geração mais jovem ou emergente.

De acordo com Kotler e Keller (2014), os fatores pessoais também afetam o consumo. Alguns exemplos de características pessoais que podem influenciar a decisão de compra são a idade, estágio no ciclo de vida, ocupação, situação econômica, personalidade, estilo de vida, valores e autoimagem. Diniz (2012) observa que o indivíduo escolhe para consumir produtos que não são efetivamente necessários, caracterizando o consumo como motivado por desejos. Estes desejos motivam o consumo por estimularem estágios de tensão, saciados após a obtenção do bem desejado.

Catry (2003) constata ser possível perceber que alguns perfis de consumidores estão mais focados em qualidade e atendimento do que, necessariamente, em preços - ou seja, estão dispostos a despender um valor mais elevado para receber um custo benefício maior. Yoshida (2011) constata que essa pré-disposição faz com que o mercado de produtos Premium seja mais procurado, já que a ideia deste segmento é proporcionar um produto de qualidade superior, com maior valor agregado, proporcionando uma melhor experiência de compra.

Além disso, um estudo realizado pela Data Popular/ Serasa Experian (2014), mostrou que 54\% da população do Brasil é de classe média, sendo que em 2003 eram apenas 38\%. O estudo mostrou também que existem previsões que a dita "classe C $C$ " chegue a $58 \%$ da população em 2023. Os gastos da chamada "classe média" (composta por 108 milhões de pessoas, de acordo com os dados da pesquisa) foram acima de $\mathrm{R} \$ 1,17$ trilhão em 2013, movimentando $58 \%$ do crédito no Brasil.
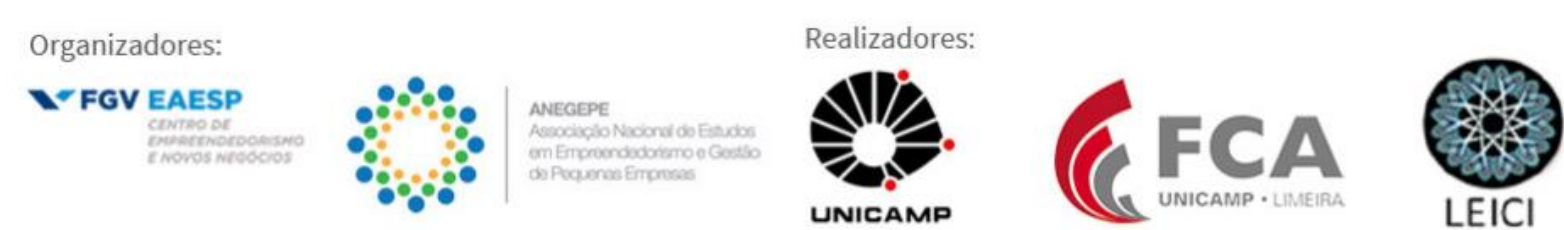
Fica evidente a melhora da situação econômica dos brasileiros nos últimos anos, consequentemente aumentando o poder de consumo da população. A ascensão das classes média e alta promove gastos mais elevados com produtos Premium, já que tais populações, com maior poder aquisitivo e crédito (YOSHIDA, 2011) possuem maior poder de compra e tendem a optar por produtos de melhor qualidade. Dessa forma, é compreensível que este segmento ganhe cada vez mais atenção e relevância em estudos organizacionais, sendo importante a realização de mais estudos correlatos - até porque, se contrariando dados macroeconômicos, como destacou Valim (2018), vários segmentos de mercado considerados Premium não cessaram seu crescimento, ainda que submetidos a uma situação de crise econômica desde meados de 2015.

\section{Resultados da pesquisa}

\subsection{Perfil do entrevistado}

O entrevistado da Empresa A (Entrevistado A) tem 40 anos de idade, é formado em propaganda e marketing e, possui o empreendimento de espetinhos Gourmet, inaugurado em 2016, e também é sócio de uma empresa de publicidade. O entrevistado da Empresa B (Entrevistado B) tem 32 anos, é formado em administração, com Pós-Graduação em finanças e é diretor do projeto imobiliário Premium inaugurado em 2016. Por fim, o entrevistado da Empresa C (Entrevistado C) tem 25 anos de idade, com superior incompleto em administração e é dono de uma hamburgueria Gourmet inaugurada em 2015 (Quadro 2)

Quadro 2 - Resumo: Identificação do perfil do entrevistado

\begin{tabular}{|l|c|c|c|}
\hline & Entrevistado A & Entrevistado B & Entrevistado C \\
\hline Idade & 40 & 32 & 25 \\
\hline Escolaridade & $\begin{array}{c}\text { Graduado em } \\
\text { Propaganda e Marketing }\end{array}$ & $\begin{array}{c}\text { Graduado em } \\
\text { Administração e Pós- } \\
\text { Graduação em Finanças }\end{array}$ & $\begin{array}{c}\text { Superior incompleto em } \\
\text { Administração }\end{array}$ \\
\hline Sexo & Masculino & Masculino & Masculino \\
empreendedor & $\begin{array}{c}\text { Sim, nunca buscou } \\
\text { emprego, saiu da } \\
\text { faculdade e já abriu uma } \\
\text { empresa }\end{array}$ & $\begin{array}{c}\text { Sim, assume risco, } \\
\text { identifica e toma } \\
\text { iniciativa de atender } \\
\text { novos mercados }\end{array}$ & $\begin{array}{c}\text { Sim, tem a atitude de } \\
\text { abrir um negócio mesmo } \\
\text { em situação de } \\
\text { instabilidade econômica }\end{array}$ \\
\hline Considera-se inovador & Não & Sim & Sim \\
\hline $\begin{array}{l}\text { Considera-se uma } \\
\text { pessoa que assume } \\
\text { riscos }\end{array}$ & $\begin{array}{c}\text { Sim, apesar de ser um } \\
\text { risco calculado }\end{array}$ & Sim & \\
\hline
\end{tabular}

Fonte: Elaborado pelos autores

\subsection{Estruturação do empreendimento}

Quanto ao número de funcionários em cada empreendimento, constatou-se que a Empresa A conta com 4 pessoas, além dos terceirizados responsáveis pela limpeza. A Empresa B possui 5 trabalhadores. Já a Empresa $\mathrm{C}$ tem uma estrutura de funcionários diferenciada por atuar no ramo imobiliário. Esta possui 86 trabalhadores na obra, sendo 26 contratados e 60 terceirizados. Quanto ao setor administrativo e de suporte são 5 pessoas em Uberlândia e 
também contam com o auxílio da matriz em Brasília. O Quadro 3 apresenta a síntese destes dados.

Quadro 3-Resumo: Identificação do empreendimento

\begin{tabular}{|l|c|c|c|}
\hline & Empresa A & Empresa B & Empresa C \\
\hline Ramo de atuação & Alimentício & Imobiliário & Alimentício \\
\hline Foco & Espetinhos Gourmet & Imóvel Premium & Janeiro 2016 \\
\hline Data de abertura & Outubro 2016 & 2016 & 5 \\
\hline Funcionários & $\begin{array}{l}4+\text { limpeza } \\
\text { terceirizada }\end{array}$ & $\begin{array}{c}\text { 5, com apoio da estrutura de } \\
\text { Brasília e 82 responsáveis por obra } \\
\text { (26 contratados e 56 terceirizados) }\end{array}$ & \\
\hline
\end{tabular}

Fonte: Elaborado pelos autores

\subsection{Critérios de seleção de segmento e abertura do negócio}

Pelo fato de o Entrevistado A identificar seu empreendimento no setor publicitário como de difícil sucessão e continuidade após a aposentadoria, teve a iniciativa de abrir o empreendimento no ramo alimentício. Assim, segundo o entrevistado, existia a possibilidade de criar um modelo de negócio replicável, podendo, no futuro, transformar seu empreendimento em uma franquia, não dependendo exclusivamente de sua participação. Este motivo levou à abertura de um novo empreendimento que se assemelha ao conceito anteriormente mencionado. Observa-se que fatores pessoais influenciaram a criação do empreendimento (a relatada "necessidade de sobrevivência, descrita por Leite (2000)).

Em outra perspectiva, a Empresa $\mathrm{C}$ surgiu da busca por novas alternativas de empreendimento que atendessem a um público menos suscetível à crise econômica no Brasil. Ou seja, segundo o Entrevistado C, houve uma influência e preocupação quanto aos fatores externos, que levaram a um novo estilo de empreendimento, caracterizado como empreendimento por oportunidade - algo similar ao observado por Mariano e Mayer (2011) e Machado (2015). Isto é, apesar de já possuir uma empresa estruturada que proporcionava uma renda favorável, o Entrevistado $\mathrm{C}$ buscou uma nova oportunidade no mercado que reduzisse seus riscos e atendesse a um público que não possuía suas necessidades supridas pelo mercado.

Devido à insatisfação do Entrevistado B quanto ao seu emprego anterior, ele relatou ter optado por abrir seu próprio empreendimento para que pudesse trabalhar com maior satisfação e realização própria. Ainda segundo seu relato, o Entrevistado B "sempre se interessou pelo 9 ramo alimentício" e por isso, decidiu abrir uma hamburgueria Gourmet. Esta motivação baseada em realização corrobora o disposto por Dornelas (2007) e Leite (2000).

\subsection{Experiência prévia do empreendedor no segmento}

Os entrevistados foram questionados se já haviam trabalhado no ramo de seus respectivos empreendimentos anteriormente. Quanto ao questionamento, apenas o Entrevistado $\mathrm{C}$ já havia atuado no ramo antes. Seguindo a linha de identificação de fatores que impactaram e influenciaram a abertura destes empreendimentos, foi identificado que os Entrevistados A e B possuíam diversos familiares empreendedores, inclusive no ramo alimentício. Segundo os entrevistados, essa experiência indireta contribuiu para a abertura do empreendimento. Este ponto de vista corrobora a análise de Nyock, Ilouga e Hillervova (2013).
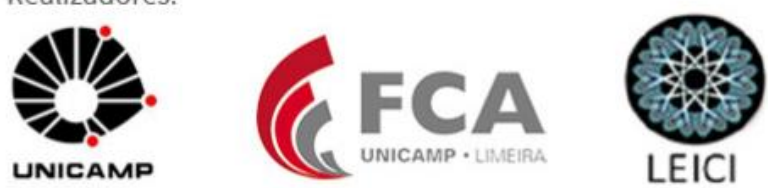
Ao responder sobre a preparação prévia para abertura do negócio, o Entrevistado A destacou que se cercou de diversos profissionais (consultores, chef famoso de cozinha, empresa financeira, dentre outros) para reduzir os riscos do empreendimento. Este posicionamento é similar ao observado por Sánchez (2013), no qual descreve a busca da minimização de riscos cotidianos por meio da verificação de processos adotados, assumindo ações de controle de riscos. Todos os entrevistados responderam que se consideram pessoas que assumem riscos, contudo, o Entrevistado A não se considerou inovador.

\subsection{Autoimagem empreendedora}

Ao serem questionados sobre se se consideram pessoas empreendedoras, os três entrevistados responderam que sim. Os Entrevistados A e B, atuantes no setor alimentício, mencionaram o fato de que desenvolver e abrir um novo negócio assumindo riscos faz com que sejam pessoas empreendedoras. O Quadro 4 apresenta a síntese das respostas dos entrevistados acerca dos motivos e influências na abertura de seus empreendimentos.

Quadro 4 - Resumo: Motivação e influências para abertura do empreendimento

\begin{tabular}{|c|c|c|c|}
\hline 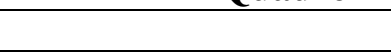 & $\begin{array}{l}\text { Entrevistado A } \\
\end{array}$ & Entrevistado B & Entrevistado $\mathrm{C}$ \\
\hline $\begin{array}{l}\text { Motivo que levou a abrir } \\
\text { o negócio }\end{array}$ & $\begin{array}{l}\text { Ter um empreendimento que } \\
\text { não necessite da presença } \\
\text { dele, que "caminhe sozinho". }\end{array}$ & $\begin{array}{c}\text { Identificação de } \\
\text { oportunidade, entrar } \\
\text { em um segmento } \\
\text { estável e atender } \\
\text { variados públicos }\end{array}$ & $\begin{array}{l}\text { Insatisfação com o } \\
\text { emprego antigo e } \\
\text { trabalhar com algo que } \\
\text { goste }\end{array}$ \\
\hline $\begin{array}{l}\text { Experiência prévia na } \\
\text { área em que atua }\end{array}$ & Não & Sim & Sim \\
\hline $\begin{array}{l}\text { Experiência prévia em } \\
\text { empreender }\end{array}$ & Sim & Sim & Não \\
\hline $\begin{array}{l}\text { Familiares } \\
\text { empreendedores }\end{array}$ & Sim & Não & Sim \\
\hline $\begin{array}{l}\text { Características pessoais } \\
\text { determinantes para } \\
\text { abertura do negócio }\end{array}$ & $\begin{array}{c}\text { Facilidade no } \\
\text { desenvolvimento de produtos } \\
\text { prezando pela qualidade e } \\
\text { diferenciação }\end{array}$ & $\begin{array}{l}\text { Busca estudos para } \\
\text { entender o mercado e } \\
\text { por novos desafios }\end{array}$ & $\begin{array}{l}\text { Persistência e paixão } \\
\text { pela comida }\end{array}$ \\
\hline $\begin{array}{l}\text { Recebeu preparação } \\
\text { prévia para abertura do } \\
\text { empreendimento (cursos, } \\
\text { consultorias, etc.) }\end{array}$ & $\begin{array}{l}\text { Sim, realização de pesquisas, } \\
\text { consultoria, mapeamento de } \\
\text { localização, etc. }\end{array}$ & $\begin{array}{l}\text { Sim, realização de } \\
\text { pesquisas e } \\
\text { consultoria }\end{array}$ & Sim, apoio do SEBRAE \\
\hline $\begin{array}{l}\text { Onde buscou viabilidade } \\
\text { financeira para abrir o } \\
\text { negócio }\end{array}$ & Recursos próprios & $\begin{array}{l}\text { Recursos próprios e } \\
\text { crédito bancário }\end{array}$ & $\begin{array}{c}\text { Recursos próprios e } \\
\text { pequena ajuda familiar }\end{array}$ \\
\hline Dificuldades na abertura & $\begin{array}{l}\text { Definições do perfil do } \\
\text { empreendimento e dos } \\
\text { produtos, identificar o público } \\
\text { alvo e como atendê-los }\end{array}$ & $\begin{array}{c}\text { Diagnosticar o } \\
\text { mercado e } \\
\text { instabilidade } \\
\text { econômica do país }\end{array}$ & $\begin{array}{c}\text { Atraso na obra, cidade } \\
\text { carente em equipamentos } \\
\text { e serviços de qualidade }\end{array}$ \\
\hline
\end{tabular}

Fonte: Elaborado pelos autores 


\subsection{Conhecimento sobre o segmento Premium}

Quando questionados sobre o significado do segmento Premium, todos os entrevistados declararam possuir uma visão em comum. Dentre as diferentes visões apresentadas, as respostas dos três entrevistados convergiram para respostas nas quais fica evidente que o segmento Premium oferece um produto de maior qualidade, envolvendo diversos aspectos, como exigência do cliente, técnica, localização, conceito, matéria prima, entre outros elementos. Para os entrevistados, é clara a visão de que o objetivo do posicionamento Premium é a diferenciação do produto em relação à concorrência.

Quando questionados em relação ao preço cobrado por seus produtos, os entrevistados apresentaram pontos de vista distintos. O Empreendedor A afirmou que o valor cobrado em seu estabelecimento é maior por ser oferecido um cardápio diferenciado e uma ambientação idem. $\mathrm{O}$ entrevistado B admitiu que seu produto tem preços acima da média do mercado local, mas comparado a outros estabelecimentos do setor alimentício também atuantes no segmento Premium, tende a apresentar preços menores. O Entrevistado $\mathrm{C}$ observa, contudo, que os preços estabelecidos no seu empreendimento são competitivos com outros empreendimentos equivalentes.

Com as respostas apresentadas, constata-se que a visão de produto Premium e o rumo que estes empreendedores seguiram se enquadra com a definição de Diniz (2012), de que os fatores que diferenciam os produtos Premium são: apresentação do produto, qualidade intrínseca deste preço elevado e exclusividade. Como citado por Galhanone e Toledo (2009), as pessoas passaram a buscar produtos e serviços que vão além das necessidades básicas, e por este motivo há um maior interesse no segmento de produtos Premium. O Quadro 5 apresenta a síntese das respostas dos entrevistados.

\section{Quadro 5 - Resumo: Compreensão do conceito de "segmento Premium"}

\begin{tabular}{|c|c|c|c|}
\hline & Empresa A & Empresa B & Empresa C \\
\hline Perfil do cliente & $\begin{array}{l}\text { Pessoas que identificam o diferencial } \\
\text { por qualidade do produto }\end{array}$ & $\begin{array}{l}\text { Público de alta renda e } \\
\text { média de } 42 \text { anos. }\end{array}$ & $\begin{array}{l}\text { Classe média/alta de } \\
\text { idade variada }\end{array}$ \\
\hline $\begin{array}{l}\text { Perfil do cliente } \\
\text { foi planejado }\end{array}$ & $\begin{array}{c}\text { Sim, mas foi uma das maiores } \\
\text { dificuldades de identificar antes da } \\
\text { abertura }\end{array}$ & $\begin{array}{l}\text { Em renda pouco mais } \\
\text { alta do previsto e idade } \\
\text { abaixo do esperado }\end{array}$ & $\begin{array}{l}\text { Sim, pela localização } \\
\text { já esperava esse } \\
\text { público }\end{array}$ \\
\hline $\begin{array}{l}\text { Preco do produto } \\
\text { acima da média }\end{array}$ & Sim, pela qualidade oferecida & $\begin{array}{l}\text { Não, está de acordo } \\
\text { com a média do } \\
\text { mercado }\end{array}$ & $\begin{array}{l}\text { Considerando os } \\
\text { produtos Premium } \\
\text { está na média para } \\
\text { baixo }\end{array}$ \\
\hline $\begin{array}{l}\text { O que é segmento } \\
\text { Premium }\end{array}$ & $\begin{array}{l}\text { Produto com qualidade superior, em } \\
\text { quesito de execução, componentes, } \\
\text { técnicas, e que se posiciona como } \\
\text { superior e proporciona elementos } \\
\text { tangíveis para provar que está acima } \\
\text { da média } \\
\end{array}$ & $\begin{array}{c}\text { Produto com um } \\
\text { conceito diferenciado e } \\
\text { que proporcionem } \\
\text { melhores benefícios ao } \\
\text { cliente }\end{array}$ & $\begin{array}{l}\text { Oferece produtos de } \\
\text { maior qualidade e que } \\
\text { atende clientes mais } \\
\text { exigentes }\end{array}$ \\
\hline $\begin{array}{l}\text { Considera seu } \\
\text { produto Premium }\end{array}$ & Sim & Sim & Sim \\
\hline
\end{tabular}

Fonte: Elaborado pelos autores 


\subsection{Motivos para atuação no segmento Premium}

Diferentes respostas foram dadas quando os entrevistados foram questionados sobre os motivos pelos quais escolheram atuar no segmento Premium. Os entrevistados A e B comentaram que a ideia inicial não era oferecer produto Premium, porém, pela qualidade e diferencial dos insumos utilizados, foi necessário cobrar um valor mais elevado. Ademais, ambos ressaltaram que possuir interesse em atender a um público com paladar mais exigente e que busca comer algo de qualidade, independente de ter de pagar mais caro por isso. Já o Entrevistado C afirmou que com a estagnação do mercado imobiliário (observada desde 2015), optou-se pela segmentação como critério de diferenciação e foco. Segundo o entrevistado, essa iniciativa buscou agregar valor ao produto e o tornar menos suscetível à instabilidade do mercado. Esse posicionamento é similar ao relatado anteriormente por Dias (2016).

Constatou-se grande preocupação dos entrevistados quanto à qualidade do serviço ofertado, sendo a questão de agregar valor ao produto uma preocupação comum entre os entrevistados. Isto se enquadra no anteriormente mencionado por Kotler e Keller (2014).

\subsection{Benefícios observados da atuação no segmento Premium}

Confirmado o conceito de produto Premium, os entrevistados responderam que a vantagem deste segmento é o próprio fato de oferecer um produto diferenciado e com qualidade. Estes fatores auxiliam na fidelização do cliente - o que torna o segmento uma das mais vantajosas opções disponíveis no mercado, por o "blindar" contra efeitos da crise econômica. Vale também destacar que quando questionados sobre o impacto da situação econômica instável do Brasil em seus negócios, todos responderam que o efeito provocado foi pequeno ou irrelevante.

Outro aspecto interessante e comum entre os empreendedores entrevistados foi que todos acompanham e visitam a concorrência para aprender e proporcionar um produto ou serviço melhor.

O Quadro 6 dispõe a síntese das informações relacionadas às percepções dos entrevistados quanto ao segmento em que atuam.

\begin{tabular}{|c|c|c|c|}
\hline \multicolumn{4}{|c|}{ Quadro 6 - Resumo: Empreendendo no "segmento Premium" } \\
\hline & Empresa A & Empresa B & Empresa $\mathbf{C}$ \\
\hline $\begin{array}{l}\text { O que motivou a } \\
\text { entrar neste } \\
\text { Segmento? }\end{array}$ & $\begin{array}{l}\text { Oferecer um produto de } \\
\text { qualidade e acessível }\end{array}$ & $\begin{array}{c}\text { Visualizava uma estagnação } \\
\text { no mercado em que atuava e } \\
\text { percebeu que, no mercado } \\
\text { Premium era possível } \\
\text { agregar valor e ficar menos } \\
\text { suscetível a instabilidade } \\
\text { econômica do país }\end{array}$ & $\begin{array}{l}\text { Queria oferecer algo que } \\
\text { prezasse pela qualidade e } \\
\text { atender um público } \\
\text { exigente }\end{array}$ \\
\hline $\begin{array}{l}\text { Vantagens do } \\
\text { segmento }\end{array}$ & $\begin{array}{c}\text { Produto visto como } \\
\text { diferenciado e de maior } \\
\text { qualidade }\end{array}$ & $\begin{array}{c}\text { Oferecer um produto } \\
\text { diferenciado e o público que } \\
\text { atende }\end{array}$ & Pouco suscetível a crise \\
\hline $\begin{array}{l}\text { Dificuldades do } \\
\text { segmento }\end{array}$ & $\begin{array}{c}\text { Identificar e atender } \\
\text { expectativas do público }\end{array}$ & Como encantar o cliente & $\begin{array}{c}\text { Encontrar mão de obra } \\
\text { qualificada }\end{array}$ \\
\hline $\begin{array}{l}\text { Aceitação produtos } \\
\text { Premium em } \\
\text { Uberlândia }\end{array}$ & $\begin{array}{c}\text { Grande, tem pessoas } \\
\text { dispostas a pagar mais } \\
\text { caro por um produto de } \\
\text { qualidade }\end{array}$ & $\begin{array}{c}\text { Grande, superou expectativa } \\
\text { de vendas }\end{array}$ & $\begin{array}{l}\text { Grande, pessoas estão se } \\
\text { preocupando em comprar } \\
\text { algo de maior qualidade }\end{array}$ \\
\hline
\end{tabular}

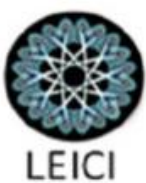




\begin{tabular}{|l|c|c|c|}
\hline $\begin{array}{l}\text { Fatores que } \\
\text { contribuem } \\
\text { empreender na } \\
\text { cidade }\end{array}$ & $\begin{array}{c}\text { Fornecedores, logística, } \\
\text { mas ainda sofre com a } \\
\text { mão de obra qualificada } \\
\text { para a operação }\end{array}$ & $\begin{array}{c}\text { Diversidade de público, } \\
\text { grandes empresas, } \\
\text { universidade forte, bem } \\
\text { localizada }\end{array}$ & $\begin{array}{c}\text { Instituições financeiras, } \\
\text { demanda }\end{array}$ \\
\hline $\begin{array}{l}\text { Segmento Premium } \\
\text { tende a crescer no } \\
\text { Brasil }\end{array}$ & $\begin{array}{c}\text { Sim, existe público para } \\
\text { este segmento }\end{array}$ & $\begin{array}{c}\text { Sim, tende a crescer bastante } \\
\text { pelo aumento da renda do } \\
\text { brasileiro }\end{array}$ & $\begin{array}{c}\text { Sim, pelo nível de } \\
\text { exigência e conhecimento } \\
\text { das pessoas }\end{array}$ \\
\hline $\begin{array}{l}\text { Instabilidade } \\
\text { econômica no país } \\
\text { afetou seu negócio } \\
\text { negativamente? }\end{array}$ & Pouco & $\begin{array}{c}\text { Foi afetado porque os } \\
\text { clientes adiam a tomada de } \\
\text { decisão, mas não deixam de } \\
\text { comprar }\end{array}$ & Não \\
\hline $\begin{array}{l}\text { Queda no consumo } \\
\text { brasileiro afetou } \\
\text { seus lucros? }\end{array}$ & Pouco & $\begin{array}{c}\text { Pouco, na questão de mão de } \\
\text { obra mais cara e pouco } \\
\text { qualificada e material mais } \\
\text { caro }\end{array}$ & $\begin{array}{c}\text { Não } \\
\text { Qual inspiração } \\
\text { para criação de } \\
\text { produtos } \\
\text { diferenciados? }\end{array}$ \\
\hline $\begin{array}{l}\text { Como lida com a } \\
\text { concorrência? }\end{array}$ & $\begin{array}{c}\text { Principais profissionais } \\
\text { da gastronomia }\end{array}$ & $\begin{array}{c}\text { Tendências de outros países } \\
\text { e pesquisa para identificar o } \\
\text { que é diferencial para o } \\
\text { cliente }\end{array}$ & $\begin{array}{c}\text { Visitou hamburguerias de } \\
\text { várias cidades. }\end{array}$ \\
\hline
\end{tabular}

Fonte: Elaborado pelos autores.

\section{Considerações Finais}

Com o estudo, é possível perceber que o empreendedorismo no Brasil é cada vez mais relevante, sendo muito importante a ampliação dos conhecimentos e estudos a respeito deste tema.

Mediante as entrevistas realizadas, foi possível se constatar que os motivadores de abertura de empreendimentos "oportunidade" e "necessidade" apontados pela teoria são corroborados. Outro aspecto relevante identificado foi a influência externa e interna associada à decisão de empreender ou não, assim como a existência de fatores antecedentes à abertura do empreendimento (novamente corroborando a teoria levantada). Igualmente correlato aos estudos levantados, cabe ressaltar que dentre as entrevistas levantadas foi possível se constatar que a abertura de um empreendimento acarreta em vários sacrifícios e riscos, calculados e pensados antes de dar início ao negócio.

Além da crescente importância do empreendedorismo (constatada tanto por métricas oficiais, como o GEM, quanto por medidas qualitativas não amostrais, como o presente estudo), percebe-se a ascensão do segmento Premium. Percebe-se a busca dos entrevistados por um segmento menos suscetível aos efeitos da crise e passível de fidelização de clientes, algo que aparentemente o segmento tem dado mostras de o fazer.

Pela fala dos entrevistados e mediante a pesquisa bibliográfica desenvolvida, percebese que ocorreu uma mudança quanto ao perfil do consumidor brasileiro, ampliando o nível de consumo e demanda por produtos do segmento Premium. Um dos fatores que pode ter provocado esta mudança é a alta concorrência e quantidade de opções no mercado, associada ao aumento do acesso a crédito pelo consumidor, o que acaba ampliando o poder de compra do
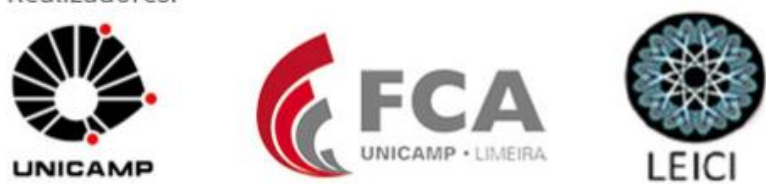
consumidor e lhe conferindo poder na relação comercial, o tornando mais exigente e mais propenso à fidelização.

Dessa forma, este segmento torna-se uma alternativa de negócio para pessoas que foram afetadas pelo desemprego ou que desejam empreender de uma forma mais segura, já que este é pouco atingido pela instabilidade econômica do país e é uma demanda cada vez maior dos consumidores brasileiros.

Com a análise das respostas concedidas pelos entrevistados, foi possível lograr todos os objetivos do artigo, sendo eles: a realização de uma análise do perfil de alguns empreendedores nesse segmento, a identificação de como esses empreendedores definem esse segmento e como eles compreendem a inserção desse tipo de empreendimento no mercado passando momento econômico atual.

Percebe-se que as entrevistas reafirmaram muitos dos conceitos teóricos levantados neste artigo, tanto sobre empreendedorismo como produtos Premium. É interessante mencionar que os estudos consultados aparentemente são bastante representativos quanto á realidade observada nestes três sujeitos entrevistados. Constatou-se, também, a relativa novidade de estudos do tema "segmento premium" na academia.

Cabe ressaltar que nenhum dos entrevistados se sentiu ameaçado com a instabilidade econômica no Brasil, sendo outro ponto positivo do empreendimento Premium, já que os consumidores deste segmento demoram mais para serem afetados por problemas econômicos no país. Isto responde ao último objetivo do artigo, já que se conclui que os empreendedores percebem esse segmento como tendo possibilidades positivas de inserção e aceitação no mercado, além de ser vantajoso em relação a outros segmentos quando se considera um momento de instabilidade econômica.

A despeito de suas contribuições teóricas, o estudo apresenta limitações destacadamente, o fato de terem sido estudados três situações selecionadas de forma não probabilística e por conveniência, o que pode originar vieses. Ademais, as empresas selecionadas para a composição da amostra são de segmentos distintos. Por estes motivos, os resultados observados quanto a esta pesquisa podem não ser representativos quanto ao universo de outras potenciais situações empresariais similares.

Como propostas de trabalhos futuros, sugere-se a realização de estudos com foco no segmento premium em amostras populacionais maiores. Ademais, sugere-se a realização de estudos relacionados ao segmento premium em ramos de negócios específicos, para a ampliação dos conhecimentos relacionados ao tema.

\section{Referências Bibliográficas}

BESSANT, J.; TIDD, J. Inovação e Empreendedorismo. Porto Alegre: Bookman, 2009.

CATRY, B.. The great pretenders: the magic of luxury goods. London Business School Review, v. 14, n. 3, p. 10-17, 2003.

CHURCHILL JR, G, A.; PETER, J. P.. Marketing: criando valor para os clientes. 13 ed. São Paulo:

Saraiva, 2013.

COOPER, D. R.; SCHINDLER, P.S.. Métodos de pesquisa em administração. 12 ed. Porto Alegre: Bookman, 2016. 
DATA POPULAR e SERASA EXPERIAN. Faces da Classe Média, Fevereiro, 2014. Disponível em: $<$ http://www.secovi.com.br/files/Arquivos/faces-da-classemedia-secovi-midia.pdf $>$. Acesso em 20 jan. 2018.

DEGEN, R. J. O empreendedor: Empreender como opção de carreira. São Paulo: Pearson Prentice Hall, 2009.

DIAS, R.. Luxo Inabalável. Conselhos. São Paulo, 2016. Disponível em: < http://www.fecomercio.com.br/upload/file/2016/04/11/conselhos_36_tela_simples.pdf >. Acesso em 12 fev. 2018.

DINIZ, C.. O Mercado do Luxo No Brasil, tendências e oportunidades. São Paulo: Semoan, 2012. DORNELAS, J. C. A. Empreendedorismo: transformando ideias em negócios. 3. ed. Rio de Janeiro: Elsevier, 2008.

DORNELAS, J. C. A. Empreendedorismo na prática: Mitos e verdades do empreendedor de sucesso. Rio de Janeiro: Elsevier, 2007. $2^{\mathrm{a}}$ reimpressão.

DRUCKER, P. F. Inovação e Espírito Empreendedor: Prática e princípios. São Paulo: Biblioteca Pioneira de Administração e Negócio, 1986.

DUBOIS, B.; CZELLAR, S.; LAURENT, G.. Consumer segments based on attitudes toward luxury: empirical evidence from twenty countries. Marketing Letters, v.16, n. 2, p. 115-128, 2005.

ENDEAVOR; GRUPO TROIANO. Cultura empreendedora no Brasil. [S.1.]. 2014. Disponível em: <https://rdstation-static.s3.amazonaws.com/cms\%2Ffiles\%2F6588\%2F1425322567ENDEAVORPESQ_PERFIS-RELAT\%C3\%93RIO_FINAL.pdf>. Acesso em 21 jan. 2018.

GALHANONE, R.F.; TOLEDO, G.L. O Supérfluo tão Necessário: Atitudes e Comportamentos de Compra de Consumidores Brasileiros de Produtos de Luxo e Sofisticados. XXXIII Encontro Nacional dos estudantes de Pós-Graduação em Administração. São Paulo. Anais...São Paulo: ENANPAD 2009. Disponível em: <http://www.anpad.org.br/admin/pdf/MKT676.pdf>. Acesso em 20 jan. 2018.

GEM - Brasil, 2016. Global Entrepreneurship Monitor: Empreendedorismo no Brasil. Relatório Executivo. Curitiba: IBPQ, 2016. <https://m.sebrae.com.br/sites/PortalSebrae/estudos_pesquisas/pesquisa-gem-empreendedorismo-nobrasil-e-no-mundodestaque9,5ed713074c0a3410VgnVCM1000003b74010aRCRD>. Acesso em 15 fev 2018.

GIL, A. C. Como elaborar projetos de pesquisa. 4. ed. São Paulo: Editora Atlas S.A., 2002.

GODOY, A. S. Introdução à pesquisa qualitativa e suas possibilidades. Revista de Administração de Empresas, v. 35, n. 2, p. 57-63, mar./abr. 1995.

HISRICH, R. D.; PETERS, M.P.; SHEPER, P.D. Empreendedorismo. 7. ed. Porto Alegre: Artmed, 2009.

KOTLER, P.; KELLER, K. L.. Administração de Marketing. 14 ed. São Paulo: Pearson Prentice Hall, 2014.

LANDSTRÖM, H.; HARIRCHI, G.; ASTRÖM, F. Entrepreneurship: Exploring the Knowledge base. Research Policy, v. 41, n. 7. p. 1154-1181, set. 2012.

LEITE, E. O Fenômeno do Empreendedorismo. Recife, Bagaço, 2000.

LONGENECKER, J. G. et al. Administração de pequenas empresas. 13 ed. São Paulo: Cengage Learning, 2007.

MACHADO C. G. et al. Empreendedorismo em cenários complexos: Uma visão da realidade atual e futura no Brasil a partir de análise comparativa. Revista de Administração IMED, Belo Horizonte, v. 5, n. 2, p. 153-165, maio/ago. 2015.

MADI, L.; AMARAL, R.. O que o brasileiro irá comer em 2020? Revista da ESPM., v. 9, n. 3, p. 7691, maio/jun. 2014.

MARIANO, S.; MAYER, V. F. Empreendedorismo: Fundamentos e Técnicas para criatividade. Rio de Janeiro: LTC, 2011. 
MATTOSO, C. L. Q.; DE SÁ, E.. A posição social, sua influência no consumo da base da pirâmide e a adoção de um novo modelo de estratificação social. Revista Brasileira de Pesquisas de Marketing, Opinião e Mídia, v. 12, p. 45-58, 2013.

NYOCK, A. C.; ILOUGA, S. N.; HIKKEROVA, L.. Intention entrepreneuriale et projet professionnel. Gestion 2000, v. 30, n. 4, p. 47-65, 2013.

PASSARELLI, S.. O Universo do Luxo - Marketing e Estratégia para o Mercado de Bens e Serviços de Luxo. São Paulo: Editora Manole Ltda, 2010.

PRODANOV, C. C.; FREITAS, E. C. Metodologia do trabalho científico: métodos e técnicas da pesquisa e do trabalho acadêmico. Nova Hamburgo: Universidade FEEVALE, 2013.

REICHHELD, F. O valor da fidelidade. HSM Management, ano 4, n. 21, jul./ago. 2000.

ROCHA, E.L. de C.; FREITAS, A. A. F. Avaliação do ensino de empreendedorismo entre estudantes universitários por meio do perfil empreendedor. RAC-Revista de Administração Contemporânea, v. 18, n. 4, 2014.

SÁNCHEZ, J. C.. The impact of an entrepreneurship education program on entrepreneurial competencies and intention. Journal of Small Business Management, v. 51, n. 3, p. 447-465, 2013.

SCHUMPETER, J. A. Capitalismo, socialismo e democracia. Rio de Janeiro: Editora Fundo de Cultura, 1961.

SEBRAE. Design Thinking: inovação pela criação de valor para o cliente. [S.1.]. 2016. Disponível em: <http://www.sebrae.com.br/sites/PortalSebrae/artigos/design-thinking-inovacao-pela-criacao-de-valorpara-o-cliente,c06e9889ce11a410VgnVCM1000003b74010aRCRD>. Acesso em 10 fev. 2018.

SILVA, H. I. D. A qualidade das padarias Gourmet e a sua estratégia de marketing na definição do perfil do consumidor. 2014. 95 f. Dissertação (Mestrado em Engenharia Alimentar) -Universidade de Lisboa, Lisboa, 2014.

STREHLAU, S.. Marketing do luxo. São Paulo: Cengage Learning, 2008 .

VALIM, C. E.. Luxo que atravessa a crise. Isto É Dinheiro. São Paulo, 2017. Disponível em: $<$ https://www.istoedinheiro.com.br/luxo-que-atravessa-crise/>. Acesso em 02 fev. 2018.

VERGA, E.; SILVA, L. F. S. Empreendedorismo: evolução histórica, definições e abordagens. Revista de Empreendedorismo e Gestão de Pequenas Empresas, v. 3, n. 3, p. 3-30, 2014.

YOSHIDA, S.. O futuro do luxo no Brasil está no crescimento da classe C. Época Negócios, São Paulo, 2011. Disponível em: <http://epocanegocios.globo.com/Revista/Common/0,EMI244135-18055,00$\mathrm{O}+\mathrm{FUTURO}+\mathrm{DO}+\mathrm{LUXO}+\mathrm{NO}+\mathrm{BRASIL}+\mathrm{ESTA}+\mathrm{NO}+\mathrm{CRESCIMENTO+DA+CLASSE+C.html}>$ Acesso em 02 fev. 2018 